\title{
Cardiovascular Effects of Right Ventricle-Pulmonary Artery Valved Conduit Implantation in Experimental Pulmonic Stenosis
}

\author{
Yuuto SAIDA ${ }^{1) *}$, Ryou TANAKA ${ }^{1)}$, Ryuji FUKUSHIMA ${ }^{1)}$, Katsuichiro HOSHI ${ }^{2)}$, Satoshi HIRA ${ }^{1)}$, \\ Aiko SODA $^{1)}$, Tomoya IIZUKA ${ }^{1)}$, Taisuke ISHIKAWA ${ }^{1)}$, Taiki NISHIMURA ${ }^{1)}$ and Yoshihisa YAMANE ${ }^{1)}$ \\ ${ }^{1)}$ Department of Veterinary Surgery, Faculty of Agriculture, Tokyo University of Agriculture and Technology, 3-5-8 Saiwai-cho, Fuchu- \\ shi, Tokyo 183-8509 and ${ }^{2)}$ Mitsuke Animal Hospital, 5-35-29 Imamachi, Mitsuke-shi, Niigata 954-0111, Japan
}

(Received 16 July 2008/Accepted 4 December 2008)

ABSTRACT. Right ventricle (RV)-pulmonary artery (PA) valved conduit (RPVC) implantation decreases RV systolic pressure in pulmonic
stenosis (PS) by forming a bypass route between the RV and the PA. The present study evaluates valved conduits derived from canine
aortae in a canine model of PS produced by pulmonary artery banding (PAB). Pulmonary stenosis was elicited using PAB in 10 con-
ditioned beagles aged 8 months. Twelve weeks after PAB, the dogs were assigned to one group that did not undergo surgical intervention
and another that underwent RPVC using denacol-treated canine aortic valved grafts (PAB+RPVC). Twelve weeks later, the rate of
change in the RV-PA systolic pressure gradient was significantly decreased in the PAB+RPVC, compared with the PAB group ( $60.5 \pm$
$16.7 \%$ vs. $108.9 \pm 22.9 \%$; $<0.01$ ). In addition, the end-diastolic RV free wall thickness (RVFWd) was significantly reduced in the
PAB+RPVC, compared with the PAB group ( $8.2 \pm 0.2$ vs. $9.4 \pm 0.7 \mathrm{~mm}$; $<0.05$ ). Thereafter, regurgitation was not evident beyond the
conduit valve and the decrease in RV pressure overload induced by RPVC was confirmed. The present results indicate that RPVC can
be performed under a beating heart without cardiopulmonary bypass and adapted to dogs with various types of PS, including "supra val-
vular" PS or PS accompanied by dysplasia of the pulmonary valve. Therefore, we consider that this method is useful for treating PS in
small animals.
KEY wORDS: angiocardiography, echocardiography, pulmonary artery banding, pulmonic stenosis, valved conduit. J. Vet. Med. Sci. 71(4): 477-483, 2009

Pulmonic stenosis (PS) is a relatively frequent congenital narrowing of the right ventricular outflow tract that occurs in about $0.1 \%$ of all dogs [10]. The three types of PS are supravalvular, subvalvular and infundibular, and the most frequent type in dogs is valvular dysplasia [11]. The obstruction causes increased resistance to right ventricle $(\mathrm{RV})$ systolic outflow and a proportional increase in RV systolic pressure. The increase in systolic wall stress (tension) stimulates concentric muscular hypertrophy of the RV wall [34]. Doppler echocardiography can noninvasively identify and determine the severity of PS. Dogs with resting pressure gradients of $>80 \mathrm{~mm} \mathrm{Hg}$ on echocardiograms between RV and pulmonary artery (PA) are at increased risk for syncope, congestive heart failure or sudden death, and surgical intervention is usually recommended $[11,14,26$, 36]. Strategies for treating severe pulmonic stenosis include pulmonary valvulotomy or valvulectomy [13], transventricular pulmonic dilation valvuloplasty [9], closed patch-graft valvuloplasty [4, 33], open patch-graft valvuloplasty [19] and balloon dilation valvuloplasty [5, 7, 20, 21, 30]. Although patch-graft valvuloplasty is an effective radical treatment for PS, circulation arrest time is limited using inflow occlusion [27] and cardiopulmonary bypass (CPB) is necessary for cardioplegic arrest [26]. On the other hand, although balloon dilation valvuloplasty is a popular strat-

\footnotetext{
* Correspondence to: Saida, Y., Department of Veterinary Surgery, Faculty of Agriculture, Tokyo University of Agriculture and Technology, 3-5-8 Saiwi-cho, Fuchu-shi, Tokyo 183-8509, Japan.

e-mail: k5104301@edu.gifu-u.ac.jp
}

egy, the results in dogs with PS accompanied by dysplasia of the pulmonic annulus and main pulmonary artery are inferior to those obtained in dogs with PS alone [7]. The present study examines the effectiveness of RV-PA valved conduit (RPVC) implantation to overcome the disadvantages of current procedures. Implantation with the RPVC decreases RV systolic pressure by forming a bypass and the procedure is less invasive because it can be performed under the beating heart. A bioprosthetic valved conduit has been used for RVOT reconstruction in human infants [1]. A PAto-PA anastomosis with supravalvular PS and a RV-to-PA anastomosis of Dacron non-valved conduits with valvular PS have been performed $[6,12]$, but the valved conduit cannot be used to treat PS in the clinical setting. The present study evaluates the applicability of a valved conduit derived from the canine aorta in a canine model of PS.

\section{MATERIALS AND METHODS}

Six male and 4 female conditioned beagles aged 8 months and weighing $8.4 \pm 1.1 \mathrm{~kg}$ (mean \pm S.D.) underwent blood tests, electrocardiography, radiography and echocardiography and all findings were within accepted normal limits. The dogs were housed in individual runs during the study under an ambient temperature of $22-23^{\circ} \mathrm{C}$ and $40-50 \%$ relative humidity, and fed with a balanced maintenance diet and water ad libitum. During all phases of this study, the dogs were handled and cared for in accordance with the standards established by Tokyo University of Agriculture and Technology (TUAT) as described in their "Guide for 
the Care and Use of Laboratory Animals”. In addition, this study was approved by the animal experimental committee of TUAT (the acceptance number was No. 17-50).

Pulmonary artery banding (PAB): Pre-anesthetic intravenous (i.v.) medication (atropine sulfate $0.04 \mathrm{mg} / \mathrm{kg}$ subcutaneously (s.c.), midazolam $0.2 \mathrm{mg} / \mathrm{kg}$ i.v. and butorphanol tartrate $0.2 \mathrm{mg} / \mathrm{kg}$ i.v.), and prophylactic antibiotics (ampicillin sodium, $50 \mathrm{mg} / \mathrm{kg}$ i.v.) were administered. Oxygen was administered via a face mask, and anesthesia was induced using propofol (3-6 mg/kg i.v.) for intubation and maintained with isofluorane in oxygen. Suxamethonium chloride $(0.2 \mathrm{mg} / \mathrm{kg}$ i.v. $)$ was administered intermittently and respiration was controlled with intermittent positive pressure ventilation. Following heparinization (heparin sodium 100 IU/kg i.v.), a Berman balloon catheter (5Fr, Arrow International Inc., Los Angeles, U.S.A.) was placed into the RV for angiography and pressure monitoring. After a median sternotomy was completed, the pericardium was incised and a pericardial cradle was created to adequately expose the RV outflow tract and the main pulmonary artery (MPA). The MPA was isolated, and polyester tape (3.3 mm wide) was passed around the pulmonary artery just distal to the pulmonary valve (Fig. 1A and B). The tape was gradually tightened until the transverse area of MPA was reduced to $70 \%$ of the original size (Fig. 1C), and then the tape was fixed at two points with a 3-0 nylon suture (Fig. 1D). The pericardium was closed, a chest drain tube was set in place and the thoracotomy was closed.

Preparation of bioprosthetic valved conduit: The canine aorta homograft was procured from beagle or mongrel dogs (weighted 11-14 kg) after euthanasia in public agency for other reasons, and aortae with abnormal macropathology were excluded from the present study. Aortae including the aortic valves were dissected under sterile conditions and excess tissue was trimmed. Both left and right coronary arterial orifices were ligated with 3-0 polypropylene (Prolene; Ethicon, New Brunswick, U.S.A.). Grafts were stored in $50 \%$ ethanol and then fixed as follows:

1. 4\% Denacol (EX-313; Nagase Chemicals Ltd., Osaka, Japan) for 2 days at room temperature.

2. Flushing with pure water for 1 day at room temperature.

3. Heparin sodium (1\%) for $1 \mathrm{hr}$ at room temperature.

The aortic arch was fixed, dissected (Fig. 2A) and sutured below the aortic valve with polypropylene (Figs. 2B and 3A). The outer diameter of the aortic valvular annulus was $11.5 \pm 1.5 \mathrm{~mm}(9.0-13.0 \mathrm{~mm})$. A bent and beveled polypropylene tube (6 and $8 \mathrm{~mm}$ inside and outside diameter; length, 4.0-4.5 cm), and low porous polytetrafluoroethylene (PTFE) fabric 1.65 mm thick (Bard PTFE felt; IMPRA Inc., Arizona, U.S.A.) were applied to the graft (Figs. 2C and 3). The PTFE felt was continuously sutured to a conduit on the RV wall using $5-0$ polypropylene. The completed conduits were $7.1 \pm 1.1 \times 2.8 \pm 0.5 \mathrm{~cm}$ (height $\times$ width). The internal long and short diameters of the distal conduit were 1.0 \pm 0.1

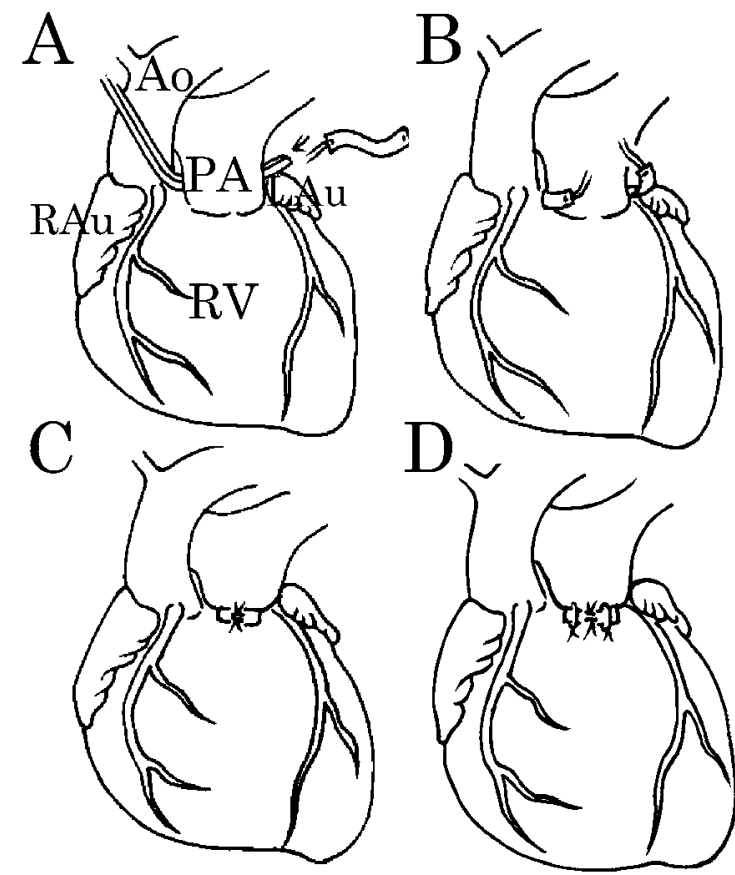

Fig. 1. A. Main pulmonary artery isolation. B. Polyester tape (3.3 mm wide) is passed around pulmonary artery. C. Tape is gradually tightened and fixed using $3-0$ nylon suture. D. Tape is fixed at two points.

and $0.8 \pm 0.1 \mathrm{~cm}$. After these procedures, grafts were stored in $30 \%$ ethanol and rehydrated in $0.9 \%$ saline for $48 \mathrm{hr}$ before implantation.

Implantation of RPVC: Ten dogs underwent $\mathrm{PAB}$ and then 12 weeks later were assigned to $\mathrm{PAB}(\mathrm{n}=5)$ or PAB+RPVC $(n=5)$ groups. Dogs in the PAB group received no treatment throughout the experimental period, whereas the PAB+RPVC group underwent RPVC. The anesthetic and premedication protocol was the same as that applied during the PAB operation. Left intercostal thoracotomy proceeded through the 4th intercostal space, and the adhesion between the chest wall and lung was separated. The pericardium was then opened to expose the right outflow tract and a buttressed mattress suture was temporarily positioned using 1-0 braided silk. The poststenotic dilatation was isolated from its connective tissue envelope and the MPA was gently retracted with two sutures. A partially occluding vascular clamp was placed on the isolated MPA and a longitudinal incision was created to accommodate the circumference of the graft. An end-to-side anastomosis between the valved conduit and MPA was constructed using a 5-0 polypropylene running suture. The conduit was declamped and air was evacuated from the conduit. The anastomosis was completed, the partial occluding clamp was slowly removed from the MPA and then an incision was made in the RV using a scalpel. A 6-mm-diameter aortic punch was introduced over this incision into the left ventricle to cut a round hole for the conduit tube, which was then 

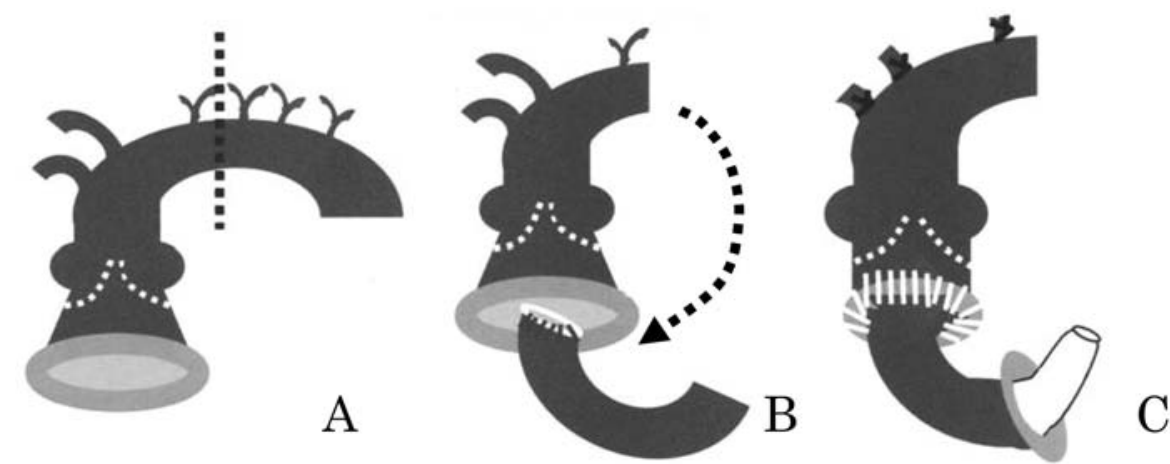

Fig. 2. Conduit construction. Aortic arch is dissected at broken line (A) and sutured below aortic valve with polypropylene (B). Brachiocephalic trunk and left subclavian artery are ligated (C), and then bent, beveled polypropylene tubing and low porous polytetrafluoroethylene (PTFE) fabric were attached to graft.

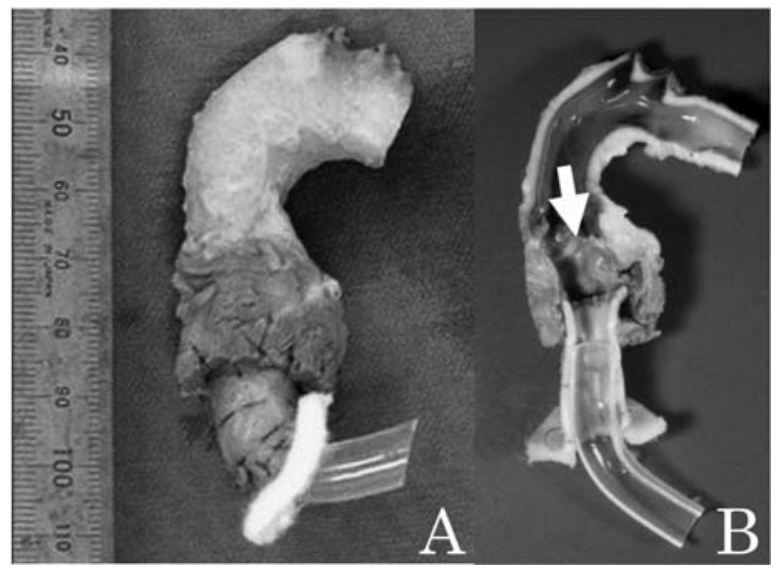

Fig. 3. Valved conduit derived from canine aorta. Valved conduit used for implantation (A). Internal structure of valved conduit (B). Arrow shows aortic valve.

fixed with a 5-0 polypropylene running suture between the PTFE felt and the RV wall (Fig. 3). After the suture lines were examined for hemorrhage, a drainage tube was positioned in the chest and the thoracotomy was closed. Postoperative blood pressure was monitored to maintain the noninvasive mean arterial blood pressure above $60 \mathrm{mmHg}$ and dopamine and lidocaine were administered when necessary. Supplemental oxygen was administered in the intensive care unit after the endotracheal tube was removed. Postoperative pain was managed with meloxicam $(0.2 \mathrm{mg} / \mathrm{kg}$ s.c.) and butorphanol tartrate $(0.2 \mathrm{mg} / \mathrm{kg}$ i.v., intermittent) on the day performed RPVC. Thoracic drainage was maintained to control pleural effusion. Prophylactic antibiotic therapy consisting of ampicillin sodium (30 mg/kg i.v. BID) was administered for 3 or 4 days after RPVC, then cephalexin (30 mg/kg BID) was administered per oral (p.o.) for ten days. Heparin sodium (100 IU/kg s.c. QID) was administered as anticoagulation therapy for one week after RPVC, and then warfarin sodium $(0.05 \mathrm{mg} / \mathrm{kg}$ BID) was administered (p.o.) until 4 weeks after RPVC. After that, medical treatment was not done. The dogs were stayed in the cages for hospitalization after RPVC, and on the tenth day after RPVC, removed to the general cages under an ambient temperature of $22-23^{\circ} \mathrm{C}$ and $40-50 \%$ relative humidity.

Assessment of cardiac function: Thoracic radiography, echocardiography and cardiac catheterization were performed before and at 12 weeks after RPVC.

Vertebral heart size (VHS) was measured on thoracic radiographs as described [15]. Briefly, the long and short axes of the heart were measured in left lateral radiographic views. The total length of the two axes is described as the number of thoracic vertebrae starting at the cranial edge of T4. The cardiothoracic ratio (CTR) was calculated as the ratio of the maximal distance between the median line and the cardiac silhouette to the distance between the median line and the maximal internal margins of the ribs.

On echocardiography, peak blood flow velocity of the pulmonary artery was measured in the right parasternal short axis view at the level of the aortic valve using continuous wave Doppler and pressure gradients were calculated using the modified Bernoulli equation. The end-diastolic RV free wall thickness (RVFWd), end-diastolic and the end-systolic RV internal area (RVIAd and RVIAs, respectively) were measured in the apical four chamber view from the left parasternum. The RV cavity cross-sectional area was measured by tracing the endocardial border from the tricuspid annular plane to the apex at end-systole and enddiastole [16, 17, 31]. The stroke volume through pulmonary valve (Qp) and from left ventricle (LVSV), and the flow volume from the RV into the MPA through the conduit were calculated by multiplying the velocity time integral by the area of the vessel or annulus approximating a circle [2].

Flow into the conduit 12 weeks after RPVC was assessed by angiocardiography.

Statistical analysis: Values are expressed as means \pm S.D. Differences between the PAB and PAB+RPVC groups were analyzed using unpaired $t$-tests. On the other hand, differences between before and after RPVC were analyzed using paired $t$-tests. Differences were considered statistically significant at $\mathrm{p}<0.05$. 


\section{RESULTS}

All dogs survived the PAB and RPVC procedures. The thoracic drain was removed 2 or 3 days after the surgery, except for one dog that developed pleural effusion for 2 weeks after $\mathrm{PAB}$. Although two dogs in the $\mathrm{PAB}$ group developed ascites, and the other showed no clinical signs during the observation period. One dog in the PAB+RPVC group died of intrathoracic hemorrhage at 3 weeks after RPVC. However, blood flow into the conduit was maintained and echocardiography showed that the valve was functional. The conduit remained patent and occlusion was not evident at necropsy. In addition, thrombi were not found in the polypropylene tube, PTFE felt, valvular area or at the anastomosis to the MPA.

Thoracic radiography showed that the VHS and CTR did not significantly differ before and 12 weeks after RPVC.

Echocardiography revealed that pressure gradients was slightly increased to $137.1 \pm 44.0 \mathrm{mmHg}$ in the PAB group, but significantly decreased to $61.9 \pm 22.2 \mathrm{mmHg}$ in the PAB+RPVC group at 12 weeks after RPVC $(\mathrm{p}<0.01$, Table $1)$. At that time, the rates of change in pressure gradients between before and after RPVC were $108.3 \pm 22.9 \%$ and $60.5 \pm 16.7 \%$ in the $\mathrm{PAB}$ and $\mathrm{PAB}+\mathrm{RPVC}$ groups, respectively ( $p<0.01$, Table 1 ). Before RPVC, in the values of the RVFWd in the PAB and PAB+RPVC groups were $9.0 \pm 0.7$ and $8.0 \pm 0.7 \mathrm{~mm}$ respectively (no significant difference). However, at 12 weeks after RPVC, RVFWd was significantly reduced in the $\mathrm{PAB}+\mathrm{RPVC}$, compared with the $\mathrm{PAB}$ group ( $8.2 \pm 0.2$ vs. $9.4 \pm 0.7 \mathrm{~mm} ; \mathrm{p}<0.05$, Table 1$)$. The RVIAd and RVIAs did not significantly differ between the $P A B$ and $P A B+R P V C$ groups. However, in the $\mathrm{PAB}+\mathrm{RPVC}$ group, RVIAd and RVIAs after RPVC tended to decrease between before and after RPVC. On the other hand, pulmonic insufficiency was not detected in either of the groups.

Although LVSV and RVSV did not differ between the two groups, LVSV tended to slightly increase in the $\mathrm{PAB}+\mathrm{RPVC}$ compared with the PAB group, which decreased after RPVC. The Qp/LVSV (= Qp/Qs) significantly decreased in the $\mathrm{PAB}+\mathrm{RPVC}$ group after RPVC $(\mathrm{p}<0.05$, Table 1). On the other hand, cardiac output (CO) and heart rate (HR) did not significantly differ between the two groups.

Cardiac catheterization found no displacement of the band and poststenotic dilatation was evident at 12 weeks after PAB (Fig. 4A).

Before RPVC, right ventricular systolic pressure (RVSP) did not significantly differ between the PAB and $\mathrm{PAB}+\mathrm{RPVC}$ groups. However, at 12 weeks after RPVC, RVSP was significantly decreased in the PAB+RPVC, compared with the PAB group $(44.0 \pm 8.5$ vs. $70.6 \pm 16.1$ mmHg; $\mathrm{p}<0.05$, Table 1).

Angiography at 12 weeks after RPVC confirmed conduit patency (Fig. 4B) and the absence of regurgitation through the valve of the conduit from the MPA (Fig. 4C).

\section{DISCUSSION}

This is the first study to examine the effects of bioprosthetic valved conduit implantation in PS model dogs. The key benefit of RPVC is that it can proceed under the beating heart without a cardiopulmonary bypass. The valved conduit can also be adapted for dogs with various type of PS, including the rare "supra valvular PS" for which balloon dilation valvuloplasty is not recommended. Therefore, we consider that RPVC should be useful for all type of PS from a technical viewpoint.

Furthermore, RPVC confers some hemodynamic benefits. The PS model dogs developed RV pressure overload

Table 1. Cardiac parameters between PAB and PAB+RPVC groups

\begin{tabular}{|c|c|c|c|c|}
\hline & \multicolumn{2}{|c|}{ Before RPVC } & \multicolumn{2}{|c|}{$12 \mathrm{w}$ after RPVC } \\
\hline & PAB & $\mathrm{PAB}+\mathrm{RPVC}$ & PAB & PAB+RPVC \\
\hline PG (mmHg) & $126.8 \pm 35.8$ & $102.1 \pm 16.4$ & $137.1 \pm 44.0$ & $61.9 \pm 22.2 * * \#$ \\
\hline PG-change ratio (\%) & & & $108.9 \pm 22.9$ & $60.5 \pm 16.7 * *$ \\
\hline RVFWd (mm) & $8.8 \pm 0.5$ & $8.0 \pm 0.7$ & $9.3 \pm 0.8$ & $8.2 \pm 0.2^{*}$ \\
\hline $\operatorname{RVIAd}\left(\mathrm{cm}^{2}\right)$ & $5.7 \pm 2.3$ & $6.6 \pm 2.2$ & $6.2 \pm 2.3$ & $5.0 \pm 1.0$ \\
\hline RVIAs $\left(\mathrm{cm}^{2}\right)$ & $4.1 \pm 1.6$ & $3.7 \pm 1.9$ & $4.2 \pm 1.3$ & $2.9 \pm 0.7$ \\
\hline $\operatorname{RVSV}(\mathrm{ml})$ & $13.4 \pm 2.7$ & $12.9 \pm 4.5$ & $10.4 \pm 3.6$ & $9.4 \pm 3.9$ \\
\hline $\operatorname{LVSV}(\mathrm{m} l)$ & $13.6 \pm 6.1$ & $14.6 \pm 4.8$ & $11.4 \pm 3.3$ & $15.0 \pm 3.1$ \\
\hline Flow volume from & & & & \\
\hline conduit to MPA $(\mathrm{ml})$ & - & - & - & $6.9 \pm 4.5$ \\
\hline Qp/Qs & $1.0 \pm 0.4$ & $1.1 \pm 0.6$ & $0.9 \pm 0.4$ & $0.6 \pm 0.5^{\ddagger}$ \\
\hline HR (bpm) & $116.6 \pm 29.2$ & $106.6 \pm 19.5$ & $116.4 \pm 44.0$ & $84.0 \pm 11.2$ \\
\hline $\mathrm{CO}(\mathrm{l} / \mathrm{min})$ & $1.6 \pm 0.5$ & $1.5 \pm 0.3$ & $1.3 \pm 0.5$ & $1.3 \pm 0.3$ \\
\hline RVSP (mmHg) & $66.4 \pm 14.1$ & $72.8 \pm 27.9$ & $70.6 \pm 16.1$ & $44.0 \pm 8.5 *$ \\
\hline
\end{tabular}

Values are expressed as means \pm SD. Significant difference compared with pulmonary artery banding (PAB) group at $\mathrm{p}<0.05\left(^{*}\right)$ and $\mathrm{p}<0.01(* *)$ and compared with value before RPVC at $\mathrm{p}<0.05\left(^{\ddagger}\right)$ and at $\mathrm{p}<0.01\left({ }^{\ddagger \ddagger}\right)$, respectively. PG, systolic pressure gradients between right ventricle and pulmonary artery; PG-change ratio: ratio of PG change between before and 12 right ventricular internal area; RVSV, stroke volume from right ventricle; LVSV: stroke volume from left ventricle; Qp/Qs, RVSV invasion of LVSV; HR, heart rate; CO, cardiac output; RVSP, right ventricular systolic pressure. 


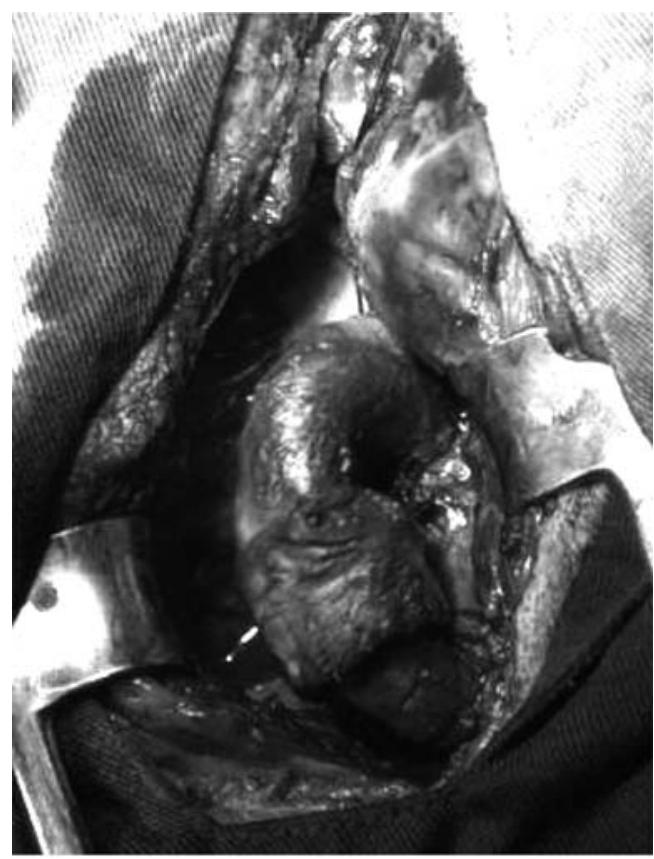

Fig. 4. Right ventricle-pulmonary artery valved conduit implantation. Above, main pulmonary artery; below, right ventricle.

and hypertrophy, and pressure gradients as well as the hypertrophy became more evident when RPVC was not applied. These changes contributed to a decrease in RV compliance because of the severe hypertrophy that can occur after PAB $[8,18,26]$. In the present study, the pressure gradients were evaluated based on modified Bernoulli equation, given the blood flow from RV into PA considerations, the limitation of echocardiography was occurred. However, on cardiac catheterization, RVSP was also decreased in the PAB+RPVC group, it was suggested that RV pressure overload was improved by RPVC. Therefore, RPVC apparently prevented progression of the RV pressure overload, then inhibited hypertrophy and increased the RVIAd to compensate the decrease in stroke volume from the RV secondary to afterload [3, 9, 24, 29, 32]. This results indicated that RVIAs decreased in the PAB+RPVC group and after RPVC compared with an increase in the PAB group [25]. On the other hand, this indicated increased RV contractility in the PAB+RPVC group through the reduced $\mathrm{RV}$ afterload derived from flow through the conduit [28]. Thus, CO was maintained by the decreased HR in the $\mathrm{PAB}+\mathrm{RPVC}$ group. One report indicates that $\mathrm{CO}$ does not differ between dogs with $\mathrm{PAB}$ and with released $\mathrm{PAB}$, although HR slightly decreases in dogs with a decreased RV pressure overload induced by releasing PAB [23]. Therefore, this indicated that PRVC induced an increase in RVSV and LVSV.

Consequently, the stroke volume of RV was the sum of the RVSV through pulmonary valve plus flow through the conduit. Stroke volume from the RV then increased, and the volume of return flow to the $\mathrm{LV}$ was increased in the $\mathrm{PAB}+\mathrm{RPVC}$ group. Therefore, these hemodynamics might be reflected in a decrease in Qp/Qs because the flow volume thorough pulmonary valve was decreased by the flow volume through the conduit.

Some degree of pulmonic insufficiency might be associated with current surgical techniques for PS [35] in humans, except for RPVC. The present study showed that RPVC produced excellent blood flow through the conduit. Pulmonic insufficiency did not arise because the original pulmonary arterial valve of the recipient had not been damaged during the surgery. In addition, the valve in the conduit prevented regurgitation from the MPA to the RV. Reports indicate that myocardial hypertrophy generally regresses and dilatation occurs secondarily to valvular insufficiency. In that case, exercise intolerance and signs of right-sided heart failure develop in humans with pulmonary valve insufficiency. In addition, use of a valve system is essential for a more favorable long-term prognosis [22].

The RPVC procedure has some limitations for clinical PS patients. The RV internal area was enlarged in our PS

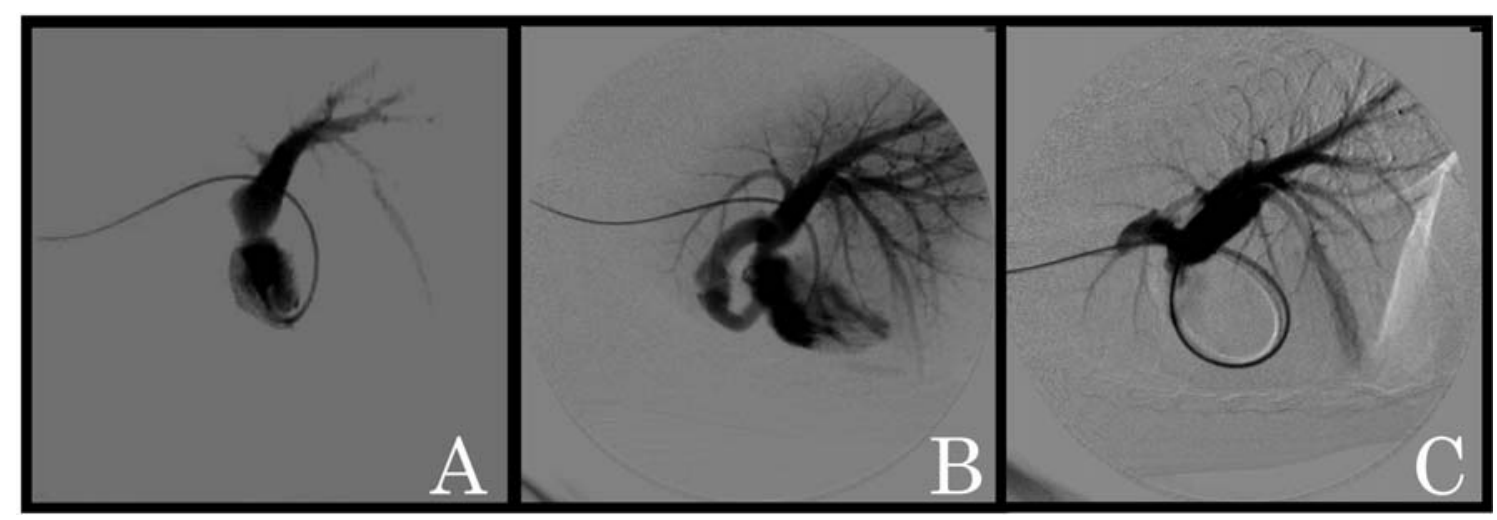

Fig. 5. Angiocardiography before and after RPVC implantation. View from right ventricle before (A), and 12 weeks after (B) RPVC; view from main pulmonary artery at 12 weeks after RPVC (C). Fine blood flow was observed from the right ventricle (RV) into pulmonary artery (PA). On the other hand, a regurgitation from PA into RV was not appeared. 
model dogs. However, clinical patients with PS have a narrow RV internal space due to severe RV concentric hypertrophy, which might render punching out the RV and positioning on the wall difficult. Therefore, whether the present RPVC method is applicable to spontaneous PS should be investigated.

The conduit remained patent in a dog that died at three weeks after RPVC and ruptures, and thrombi in the conduit or accessories to the conduit were not evident. However, the aortic valvular annulus of the conduit used in the dog was the largest (outer diameter, $13 \mathrm{~mm}$ ) in the PAB+RPVC group. In addition, pathological finding revealed pulmonary hyperemia and haemorrhage, we considered that the cause of death was excessive volume flowing from the conduit to the pulmonary vessel, which ruptured the pulmonary vessel and caused intrathoracic hemorrhage. Therefore, the safety of RPVC is necessary to pursue. In addition, the optimal size of the conduit should be defined, since RV pressure overload in patients might be further decreased by a more suitable conduit.

In conclusion, the effectiveness of RPVC for PS model dogs was suggested in the present study. Therefore, RPVC can be adapted for supra valvular PS or PS with hypoplasia of the pulmonary valvular annulus.

\section{REFERENCES}

1. Boethig, D., Thies, W.R., Hecker, H. and Breymann, T. 2005. Mid term course after pediatric right ventricular outflow tract reconstruction: a comparison of homografts, porcine xenografts and Contegras. Eur. J. Cardiothorac. Surg. 27: 58-66.

2. Boon, J.A. 1998. Evaluation of size, function, and hemodynamics. pp. 220. In: Manual of Veterinary Echocardiography, 1st ed.,Williams \& Wilkins, Baltimore, London.

3. Braun, M.U., Szalai, P., Strasser, R.H. and Borst, M.M. 2003. Right ventricular hypertrophy and apoptosis after pulmonary artery banding: regulation of PKC isozymes. Cardiovasc. Res. 59: 658-667.

4. Breznock, E.M. and Wood, G.L. 1976. A patch-graft technique for correction of pulmonic stenosis in dogs. J. Am. Vet. Med. Assoc. 169: 1090-1094.

5. Bright, J.M., Jennings, J., Toal, R. and Hood, M.E. 1987. Percutaneous balloon valvuloplasty for treatment of pulmonic stenosis in a dog. J. Am. Vet. Med. Assoc. 191: 995-996.

6. Buchanan, J.W. 1990. Pulmonic stenosis caused by single coronary artery in dogs: four cases (1965-1984). J. Am. Vet. Med. Assoc. 196: 115-120.

7. Bussadori, C., DeMadron, E., Santilli, R.A. and Borgarelli, M. 2001. Balloon valvuloplasty in 30 dogs with pulmonic stenosis: effect of valve morphology and annular size on initial and 1-year outcome. J. Vet. Intern. Med. 15: 553-558.

8. Chen, E.P., Craig, D.M., Bittner, H.B., Davis, R.D. and Van Trigt, P. 1998. Pharmacological strategies for improving diastolic dysfunction in the setting of chronic pulmonary hypertension. Circulation 97: 1606-1612.

9. Corno, A.F., Sekarski, N., Bernath, M.A., Payot, M., Tozzi, P. and von Segesser, L.K. 2003. Pulmonary artery banding: longterm telemetric adjustment. Eur. J. Cardiothorac. Surg. 23: 317-322.

10. Eyster, G.E. 1993. pp. 901-907. A Text book of Small Animal
Surgery. 2nd ed., B. W. Saunders, Philadelphia.

11. Feneley, M. and Gavaghan, T. 1986. Paradoxical and pseudoparadoxical interventricular septal motion in patients with right ventricular volume overload. Circulation 74: 230-238.

12. Ford, R.B., Spaulding, G.L. and Eyster, G.E. 1978. Use of an extracardiac conduit in the repair of supravalvular pulmonic stenosis in a dog. J. Am. Vet. Med. Assoc. 172: 922-925.

13. Gibbons, J.H., Hopkinson, M. and Chrchill, E.D. 1932. Change in the circulation produced by gradual occlusion of the pulmonary artery. J. Clin. Invest. 11: 543-553.

14. Haggard, G.E. and Walker, A.M. 1923. The physiology of pulmonary embolism as disclosed by quantitative occlusion of the pulmonary artery. Arch. Surg. 5: 764-783.

15. Hansson, K., Haggstrom, J., Kvart, C. and Lord, P. 2002. Left atrial to aortic root indices using two-dimensional and M-mode echocardiography in cavalier King Charles spaniels with and without left atrial enlargement. Vet. Radiol. Ultrasound. 43: 568-575.

16. Helbing, W.A., Bosch, H.G., Maliepaard, C., Rebergen, S.A., van der Geest, R.J., Hansen, B., Ottenkamp, J., Reiber, J.H. and de Roos, A. 1995. Comparison of echocardiographic methods with magnetic resonance imaging for assessment of right ventricular function in children. Am. J. Cardiol. 76: 589-594.

17. Hiraishi, S., DiSessa, T.G., Jarmakani, J.M., Nakanishi, T., Isabel-Jones, J.B. and Friedman, W.F. 1982. Two-dimensional echocardiographic assessment of right ventricular volume in children with congenital heart disease. Am. J. Cardiol. 50: 1368-1375.

18. Hirao, H., Inoue, T., Hoshi, K., Kobayashi, M., Shimamura, S., Shimizu, M., Tanaka, R., Takashima, K., Mori, Y., Noishiki, Y. and Yamane, Y. 2005. An experimental study of apico-aortic valved conduit (AAVC) for surgical treatment of aortic stenosis in dogs. J. Vet. Med. Sci. 67: 357-362.

19. Hunt, G.B., Pearson, M.R., Bellenger, C.R. and Malik, R. 1993. Use of a modified open patch-graft technique and valvulectomy for correction of severe pulmonic stenosis in dogs: eight consecutive cases. Aust. Vet. J. 70: 244-248.

20. Johnson, M.S. and Martin, M. 2004. Results of balloon valvuloplasty in 40 dogs with pulmonic stenosis. J. Small. Anim. Pract. 45: 148-153.

21. Johnson, M.S., Martin, M., Edwards, D., French, A. and Henley, W. 2004. Pulmonic stenosis in dogs: balloon dilation improves clinical outcome. J. Vet. Intern. Med. 18: 656-662.

22. Breznock, E.M. 1990. Surgical Relief of Pulmonic Stenosis. pp. 517-520. In: Current Techniques in Small Animal Surgery, 3rd ed. (Joseph, M.B., Stephen, J.B. and James, L.T. eds.), Lea. \&. Febiger, Philadelphia.

23. Kerbaul, F., Brimioulle, S., Rondelet, B., Dewachter, C., Hubloue, I. and Naeije, R. 2007. How prostacyclin improves cardiac output in right heart failure in conjunction with pulmonary hypertension. Am. J. Respir. Crit. Care. Med. 175: 846850.

24. Kingma, I., Tyberg, J.V. and Smith, E.R. 1983. Effects of diastolic transseptal pressure gradient on ventricular septal position and motion. Circulation 68: 1304-1314.

25. Leeuwenburgh, B.P., Steendijk, P., Helbing, W.A. and Baan, J. 2002. Indexes of diastolic RV function: load dependence and changes after chronic RV pressure overload in lambs. Am. $J$. Physiol. Heart. Circ. Physiol. 282: H1350-H1358.

26. Orito, K., Yamane, T., Kanai, T., Fujii, Y., Wakao, Y. and Matsuda, H. 2004. Time course sequences of angiotensin converting enzyme and chymase-like activities during development of right ventricular hypertrophy induced by pulmonary 
artery constriction in dogs. Life. Sci. 75: 1135-1145.

27. Orton, E.C., Bruecker, K.A. and McCracken, T.O. 1990. An open patch-graft technique for correction of pulmonic stenosis in the dog. Vet. Surg. 19: 148-154.

28. Pyle, R.L., Patterson, D.F. and Chacko, S. 1976. The genetics and pathology of discrete subaortic stenosis in the Newfoundland dog. Am. Heart. J. 92: 324-334.

29. Rose, C.E. Jr, Van Benthuysen, K., Jackson, J.T., Tucker, C.E., Kaiser, D.L., Grover, R.F. and Weil, J.V. 1983. Right ventricular performance during increased afterload impaired by hypercapnic acidosis in conscious dogs. Circ. Res. 52: 76-84.

30. Salisbury, P.F. 1955. Coronary artery pressure and strength of right ventricular contraction. Circ. Res. 3: 633-638.

31. Silverman, N.H. and Hudson, S. 1983. Evaluation of right ventricular volume and ejection fraction in children by two-dimensional echocardiography. Pediatr. Cardiol. 4: 197-203.

32. Sonesson, S.E., Fouron, J.C., Teyssier, G., Skoll, A. and Chartrand, C. 2004. Immediate and short-term effects of pulmonary artery banding on left ventricular performance in foetal sheep. Acta. Paediatr. 93: 540-544.

33. Staudte, K.L., Gibson, N.R., Read, R.A. and Edwards, G.A. 2004. Evaluation of closed pericardial patch grafting for management of severe pulmonic stenosis. Aust. Vet. J. 82: 33-37.

34. Takagi, K., Fukunaga, S., Nishi, A., Shojima, T., Yoshikawa, K., Hori, H., Akashi, H. and Aoyagi, S. 2006. In vivo recellularization of plain decellularized xenografts with specific cell characterization in the systemic circulation: histological and immunohistochemical study. Artif. Organs 30: 233-241.

35. Tulevski, I.I., Hirsch, A., Dodge-Khatami, A., Stoker, J., van der Wall, E.E. and Mulder, B.J. 2003. Effect of pulmonary valve regurgitation on right ventricular function in patients with chronic right ventricular pressure overload. Am. J. Cardiol. 92: 113-116.

36. Uechi, M., Shimizu, A. and Mizuno, M. 2002. Heart rate modulation by sympathetic nerves in dogs with heart failure. J. Vet. Med. Sci. 64: 1023-1029. 